\title{
A CONSTRUÇÃO DE TÍTULOS DESVIANTES NO JORNALISMO POPULAR
}

\author{
Wagner Alexandre dos Santos Costa
}

\begin{abstract}
RESUMO
Apresenta-se, neste artigo, um estudo sociocognitivo sobre o processamento do texto em notícias populares. Foi realizado um experimento sobre a relação entre as antecipaçóes motivadas pela leitura do título e, posteriormente, pelo entendimento global do texto após sua leitura completa. Cinquenta e dois informantes realizaram atividades-teste com base em duas notícias extraídas do jornal popular Meia Hora.
\end{abstract}

PALAVRAS-CHAVE: Sociocognitivismo; Leitura; Jornalismo popular.

\section{Considerações iniciais}

"O conhecimento não consiste apenas em uma coleção estática de conteúdos e experiências, mas também em habilidades para operar sobre tais conteúdos e utilizá-los na interação social." (KOCH, 2002, p. 37)

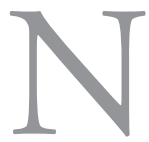

a atividade de processamento do texto, o leitor realiza diversas operações, como construir e reconstruir hipóteses sobre o texto em questão, tendo como referência vários elementos, tais como o gênero, o autor, o estilo, a finalidade do texto, entre outros.

Este trabalho trata de um estudo sobre leitura como processo dinâmico, tal como postulado nos estudos sociocognitivistas por Kleiman (2008); Solé (1998); Dell'Isola (2001); Rojo (2004); van Dijk (2002); e van Dijk e Kintsch 
(2004[1983]). Tem como base, ainda, os estudos de Costa (2013) sobre títulos desviantes. Realizamos um experimento que visou à compreensão da relação entre as antecipaçôes motivadas pela leitura inicial de notícias (ainda no título) e a atribuição do tema global do texto, inferido após sua leitura completa. $\mathrm{O}$ subgênero textual privilegiado foi a notícia popular, do jornalismo popular, tal como entendido por Amaral (2006, p. 15-16):

São jornais baratos, com baixa paginação, vendidos em bancas, que abrigam publicidades de produtos destinados ao público de baixa renda, embora ainda atendam a ínfima parcela da população. Também pressuponho que esse segmento da imprensa se utiliza de elementos culturais historicamente destinados aos setores populares ou produzidos por eles.

Os textos foram extraídos do jornal popular Meia Hora. A metodologia do trabalho envolveu três etapas: a primeira, em que os informantes leram apenas título; a segunda, em que leram um conjunto de título e subtítulo; a terceira, em que leram o texto completo, composto de título, subtítulo e corpo do texto. Nossa hipótese principal foi a de que a leitura do título geraria antecipaçôes sobre o tema que não se confirmariam ao final do procedimento completo de leitura. Os resultados do experimento confirmam essa hipótese, pois os informantes inferiram temas globais distintos entre a primeira e a terceira etapa.

\section{Fundamentação teórica}

Optamos por iniciar esta seção conceituando atividade de leitura. Adotamos, então, a seguinte definição de Kleiman (2008, p. 65), que entende ser

(...) uma interação a distância entre leitor e autor via texto.

(...) [Trata-se de uma atividade em que] o leitor constrói, e não apenas recebe, um significado global para o texto; ele procura pistas formais, antecipa essas pistas, formula e reformula hipóteses, aceita ou rejeita conclusóes. Contudo, não há reciprocidade com a ação do autor, que busca, essencialmente, 
a adesão do leitor, apresentando para isso, a melhor maneira possível, os melhores argumentos, a evidência mais convincente da forma mais clara possível, organizando e deixando no texto pistas formais a fim de facilitar a consecução de seu objetivo.

Consideramos essa definição de leitura como atividade bastante afinada à abordagem neste estudo porque tal definição pressupóe um sujeito intencional, envolvido ativamente ${ }^{1}$ em uma atividade estratégica de (re)construção de sentidos e que mobiliza uma gama de recursos cognitivos para realizá-la. Além disso, porque permite supor que as representações sobre a realidade não são evidentes e simétricas no processo de interlocução, envolvendo, pois, colaborações mútuas.

Também Dell'Isola (2001, p. 37) define leitura como atividade interativa ao dizer que "Ler é interagir, é construir significado para o texto". Segundo ela, o leitor mobiliza várias habilidades nesse processo: noçóes e crenças sobre o mundo e conhecimentos sobre a organização, a estrutura e os diferentes gêneros de texto, bem como competências lexicais, sintáticas, semânticas, discursivas e pragmáticas.

Nessa atividade de leitura/construção do sentido, segundo Kleiman (2008, p. 13), o papel do conhecimento prévio (linguístico, textual, de mundo) figura como fundamental, visto que o sentido do texto é construído a partir da relação com o que o leitor já sabe.

Assim, é preciso que autor e leitor se comuniquem em uma língua conhecida por ambos e que dominem certas noçóes e conceitos sobre o texto, por exemplo, sobre as estruturas e tipos de texto mobilizados no discurso.

Não menos importante é o conhecimento de mundo, que envolve as experiências vivenciadas e compartilhadas pelas pessoas e que podem ser mobilizadas no preenchimento de lacunas no processo de interpretação. Dessa forma, como diz Kleiman (2008, p. 25), a ativação do conhecimento prévio é de suma importância para a compreensão, visto que as inferências necessárias para relacionar diferentes partes discretas do texto em unidades coerentes dependem também do conhecimento sobre o mundo. Segundo Dell'Isola (2001, p. 44):

$\overline{1}$ Solé (1998, p. 40) também considera que na atividade de leitura e compreensão o leitor é ativo, processa e atribui significado ao que lê. 
Inferência é um processo cognitivo que gera uma informação semântica nova, a partir de uma informação semântica anterior em um determinado contexto. (...) Não ocorre apenas quando o leitor estabelece elos lexicais, organiza redes conceituais no interior do texto, mas também quando o leitor busca, extratexto, informaçôes e conhecimentos adquiridos pela experiência de vida, com os quais preenche os 'vazios' textuais.

Ainda assim, a realização de inferências não resolve o problema do processamento do texto. Por essa razão, Koch (2008a, p. 136) afirma que o leitor pode não realizar as inferências desejadas pelo escritor. Nesse caso, reconhecido o engano, o leitor poderá proceder a uma reanálise do texto mal compreendido. Conforme a autora, a maior parte dos enganos está associada ao estabelecimento de inferências não desejadas. É preciso ainda considerar que a atividade de referenciação é muitas vezes feita a "conteúdos de consciência" (KOCH, 2008b, p. 204), (re)ativados via inferenciação.

Assim, são notadamente importantes para o processamento textual tanto as informações contextuais como textuais. Nesse sentido, van Dijk e Kintsch (2004[1983] p. 26) advertem:

Ao invés de uma ativaçáo mais ou menos cega de todo um possível conhecimento na compreensão de uma palavra ou oração, ou na reconstrução global de um tema, presumiremos que o uso do conhecimento seja estratégico, que ele dependa dos objetivos do usuário da língua, da quantidade de conhecimento disponível a partir do texto e do contexto, do nível de processamento ou do grau de coerência exigido para a compreensão (...)

Dessa forma, o leitor realiza "estratégias metacognitivas" de leitura, que consistem no controle e regulamento do próprio conhecimento (KLEIMAN, 2008, p. 34). Ele é capaz, por exemplo, de decidir se compreendeu o suficiente um assunto para explicá-lo. Ou seja, pode controlar o próprio conhecimento de modo que melhor possa refletir sobre ele.

Tal ponto de vista é reiterado por Solé (1998, p. 30), ao afirmar que 
A interpretação progressiva do texto, isto é, a elaboração de sua compreensão, envolve determinar as ideias principais que ele contém. É importante estabelecer que, embora um autor possa elaborar um texto para comunicar determinados conteúdos, a ideia ou as ideias principais construídas pelo leitor dependem em grande parte dos seus objetivos de leitura, dos seus conhecimentos prévios e daquilo que o processo de leitura em si lhe oferece com relação aos primeiros.

Diz-se, então, que a atividade da leitura é dirigida pelos seus objetivos. ${ }^{2}$ Ou seja, ler uma receita de bolo requer objetivos diferentes da leitura de uma notícia de jornal ou de um anúncio de imóveis. Portanto a informação que será relevante (logo, também as estratégias empregadas na leitura) atenderá às necessidades finais do leitor. Por isso, o gênero textual se torna, nesse aspecto, de suma importância, e determina, até certo ponto, os objetivos da leitura (KLEIMAN, 2008, p. 33).

Já a formulação de hipóteses de leitura corresponde ao que o leitor pode pensar sobre o tema que o texto abordará e as conclusóes que pode antecipar com base na estrutura do texto. Van Dijk (2004[1988], p. 161) afirma que “os usuários da língua também tentam 'imaginar' do que trata o texto, por exemplo, as coisas, pessoas, atos, eventos ou estados de coisas a que o texto ou o falante se referem”. Espera-se, por exemplo, que as notícias possuam um título e que ele informe algo acerca do seu tema.

Desta forma, o leitor interage com o texto, como explica Rojo (2004, p. 6) ao discorrer sobre "as capacidades de apreciação e réplica do leitor em relação ao texto". Tais capacidades envolvidas em um processo interativo de interpretação dizem respeito a uma série de procedimentos em diferentes níveis, como a recuperação do contexto de produção do texto, a definição de finalidades e metas da atividade de leitura, a percepção de relaçóes intertextuais no nível temático e de relações interdiscursivas no nível discursivo, além da percepção dos valores estéticos da linguagem, como também atestou Costa

2 Ver em Solé (1998) os seguintes objetivos: Ler para obter uma informação precisa; Ler para seguir instruçóes; Ler para obter uma informação de caráter geral; Ler para responder; Ler para revisar um escrito próprio; Ler por prazer; Ler para comunicar um texto a um auditório; Ler para praticar a leitura em voz alta; Ler para verificar o que se compreendeu. 
(2013) em seu estudo sobre títulos desviantes no jornalismo popular.

Os aspectos desenvolvidos por Rojo reafirmam em suas bases as considerações destacadas em Kleiman, no texto supracitado.

Outro grupo de atividades cognitivas (definido anteriormente) que ressaltamos são as inferências, também relacionadas com diversas atividades de processamento textual, desde o momento de acesso ao suporte textual. Assim, de acordo com o nosso estudo, a produção de inferências baseadas na leitura do título de uma notícia é importante estratégia cognitiva na geração de hipóteses/antecipações e posteriormente na sua confirmação ou destituição.

Baseando-se nos primeiros estudos sobre a representação do conhecimento (SCHANK \& ABELSON, 1977, apud VAN DIJK, 2002, p. 252) e, ainda, em estudos sobre a compreensão do texto (JOHNSON-LAIRD, 1983; VAN DIJK \& KINTSCH, 1983; VAN OOSTENDORP \& GOLDMAN, 1999, apudVAN DIJK, 2002, p. 253), van Dijk entende que as histórias lidas nas notícias sobre um caso qualquer formam um modelo de eventos similares. Conforme se obtêm conhecimentos sobre eventos como esse, outros modelos vão se construindo, e, depois de um tempo, pode-se inferir um conhecimento geral (sobre assaltos deste tipo), conhecimento que pode ser usado na construção de modelos mentais de eventos concretos. Isto permite, por sua vez, que o jornalista formule somente a informação ainda não conhecida pelos leitores, de modo que as notícias estão incompletas, neste sentido, pois os leitores podem recuperar/inferir informaçóes necessárias com a ajuda de seu conhecimento geral. ${ }^{3}$ Como explica van Dijk (2002, p. 253), "é possível que necessitemos de modelos mentais específicos para elaborar conhecimento geral e, por outro lado, necessitemos de conhecimento geral para construir modelos mentais específicos".

\section{Um experimento de leitura: metodologia}

Expusemos 52 alunos do primeiro ano do Ensino Médio de uma escola pública estadual da cidade do Rio de Janeiro à leitura de duas notícias extra-

3 Cf. MARCUSCHI, 1985. No trabalho em que o autor apresenta uma classificação de diferentes tipos de inferências, importam especialmente as que envolvem os tipos indutivo e dedutivo de raciocínio. 
ídas do jornal popular Meia Hora. A atividade assumiu caráter de exercício, ou seja, os alunos, doravante informantes, não sabiam que se tratava de um experimento. As notícias utilizadas foram as seguintes:

$\checkmark$ O novo cardápio da cadeia: Pão com Ovo (Meia Hora, 20/08/2011)

$\checkmark$ Luan Santana morto a tiros (Meia Hora, 01/12/2011)

A atividade se dividiu em três partes, correspondentes a três testes. $\mathrm{Na}$ primeira, oferecemos aos leitores apenas o título de cada notícia e solicitamos que desenvolvessem algumas hipóteses sobre de qual assunto o título poderia tratar. Ao final de 10 minutos, recolhemos a tarefa. Na segunda, oferecemos aos leitores um conjunto composto de título e subtitulo da mesma notícia e solicitamos novamente que desenvolvessem algumas hipóteses sobre qual assunto o título poderia tratar. Ao final de 10 minutos, recolhemos a tarefa. Na terceira, oferecemos aos leitores a noticia completa: título, subtitulo (já lidos) e corpo do texto e solicitamos que respondessem qual seria o assunto principal da notícia. Ao final de 20 minutos, recolhemos a tarefa.

Com isso, objetivamos verificar as hipóteses/ antecipaçóes projetadas pelos leitores a partir da leitura da categoria título (etapa 1 - E1); posteriormente, a partir da leitura do conjunto composto por título e subtítulo (etapa 2 - E2); e, finalmente, a macroestrutura semântica ${ }^{4}$ atribuída pelos leitores à notícia completa (etapa 3 - E3):

\section{E1 - LEITURA DO TÍTULO \\ E2- LEITURA DAS CATEGORIAS PRÉ-TEXTUAIS (TÍTULO E SUBTÍTULO) \\ E3- LEITURA DA NOTÍCIA COMPLETA \\ Quanto ao experimento, nossas hipóteses sobre os resultados foram:}

4 Para van Dijk (1990, p. 54), de modo geral, um tema ou assunto é aquilo de que o discurso trata. Especifica o autor que o tema de um livro ou de uma conferência equivale mais ou menos ao que entendemos por assunto ou matéria. Trata-se do resumo ou do núcleo. Dessa forma, temas náo se definem em termos de significado de palavras ou oraçóes, mas de fragmentos textuais mais extensos; por isso, "pertencem ao macronível global da descrição do discurso". Assim, o conceito teórico empregado pelo autor para a descriçáo de temas é o de "macroestrutura semântica". 
$\checkmark$ A leitura somente do título poderia motivar hipóteses diversificadas, possivelmente distantes do conteúdo global do texto;

$\checkmark$ A leitura do título, juntamente com o subtítulo, poderia restringir mais as hipóteses da etapa anterior e os leitores poderiam atribuir macroestruturas mais próximas das que atribuiriam quando da leitura completa.

$\checkmark$ A leitura completa seria aquela etapa em que se atribuiria uma macroestrutura semântica mais próxima entre os informantes; mais semelhante àquela obtida a partir da redução semântica do texto operada por nós; mais distante das hipóteses de E1 construídas pelos próprios informantes.

Os testes foram aplicados em 20 de agosto de 2012. Observamos as respostas de todos os informantes e, em seguida, as agrupamos por semelhança e quantificamos os dados. Apresentaremos, a seguir, cada teste e os resultados referentes a cada um deles. Ao final dessa exposição, discutiremos os resultados.

\section{Os resultados}

TESTE 1: Da leitura do título

Texto 1

PLANTÁO DE POLÍCIA

O novo cardápio da cadeia: Pão com Ovo

Texto 2

PLANTÁO DE POLÍCIA

Luan Santana morto a tiros

Após a aplicação e análise, obtivemos os seguintes resultados relativos às antecipaçôes realizadas pelos informantes: 
Tabela 1- O novo cardápio da cadeia: Pão com Ovo (Etapa 1)

\begin{tabular}{|l|c|c|}
\hline $\begin{array}{c}\text { ANTECIPAÇÓES DECORRENTES } \\
\text { DA LEITURA DO TÍTULO }\end{array}$ & $\begin{array}{c}\text { QUANTIDADE } \\
\text { DE INFORMANTES }\end{array}$ & PERCENTUAL \\
\hline $\begin{array}{l}\text { Realizaram antecipaçóes acerca de de } \\
\text { cardápio alimentar. }\end{array}$ & 42 & $80,77 \%$ \\
\hline $\begin{array}{l}\text { Realizaram antecipaçóes acerca da } \\
\text { prisão de um (ou mais de um) bandido. }\end{array}$ & 10 & $19,23 \%$ \\
\hline Totais: & 52 & $100 \%$ \\
\hline
\end{tabular}

Tabela 2 - Luan Santana morto a tiros (Etapa 1)

\begin{tabular}{|l|l|l|}
\hline $\begin{array}{c}\text { ANTECIPAÇÓES DECORRENTES } \\
\text { DA LEITURA DO TÍTULO }\end{array}$ & $\begin{array}{c}\text { QUANTIDADE } \\
\text { DE INFORMANTES }\end{array}$ & PERCENTUAL \\
\hline $\begin{array}{l}\text { As antecipaçóes gerais indicam que } \\
\text { os informantes deste grupo não } \\
\text { acreditaram na possibilidade da morte } \\
\text { do cantor, mas interpretaram o nome } \\
\text { "Luan Santana" como uma referência } \\
\text { a ele. }\end{array}$ & 16 & $30,77 \%$ \\
\hline $\begin{array}{l}\text { Consideraram tratar-se da morte do } \\
\text { cantor. }\end{array}$ & 30 & $57,69 \%$ \\
\hline $\begin{array}{l}\text { Consideraram tratar-se de um homô-- } \\
\text { nimo do cantor. }\end{array}$ & 06 & $11,54 \%$ \\
\hline Totais: & 52 & $100 \%$ \\
\hline
\end{tabular}

\section{TESTE 2: Da leitura do título acrescido do subtítulo}

Texto 1

PLANTÁO DE POLÍCIA

O novo cardápio da cadeia: Páo com Ovo

Bandido foi preso no Recreio. Ele é apontado como o '02' do tráfico no Fallet e tinha plano pra matar o secretário de Administraçáo Penitenciária na Ponte Rio-Niterói 
Texto 2

PLANTÃO DE POLÍCIA

Luan Santana morto a tiros

\section{Xará do cantor levou um balaço na cabeça e outro na perna}

Após a aplicação e análise, obtivemos os seguintes resultados relativos às antecipaçóes realizadas pelos informantes:

Tabela 3 - O novo cardápio da cadeia: Páo com Ovo (Etapa 2)

\begin{tabular}{|l|c|c|}
\hline $\begin{array}{c}\text { ANTECIPAÇÕES DECORRENTES } \\
\text { DA LEITURA DO TÍTULO } \\
\text { ACRESCIDA DA LEITURA DO } \\
\text { SUBTÍTULO }\end{array}$ & $\begin{array}{c}\text { QUANTIDADE DE } \\
\text { INFORMANTES }\end{array}$ & PERCENTUAL \\
\hline $\begin{array}{l}\text { Consideraram o título como uma referência } \\
\text { ao alimento a ser oferecido na cadeia ao } \\
\text { bandido (subtítulo) preso no Recreio dos } \\
\text { Bandeirantes. }\end{array}$ & 19 & $36,54 \%$ \\
\hline $\begin{array}{l}\text { Atribuíram diretamente uma relação entre } \\
\text { a expressão "Páo com Ovo" e o bandido } \\
\text { preso. }\end{array}$ & 33 & $63,46 \%$ \\
\hline Totais: & 52 & $100 \%$ \\
\hline
\end{tabular}

Tabela 4 - Luan Santana morto a tiros (Etapa2)

\begin{tabular}{|l|c|c|}
\hline $\begin{array}{c}\text { ANTECIPAÇÓES DECORRENTES DA } \\
\text { LEITURA DO TÍTULO ACRESCIDA } \\
\text { DA LEITURA DO SUBTÍTULO }\end{array}$ & $\begin{array}{c}\text { QUANTIDADE DE } \\
\text { INFORMANTES }\end{array}$ & PERCENTUAL \\
\hline $\begin{array}{l}\text { Consideraram tratar-se de um enun- } \\
\text { ciado metafórico ou acreditaram que o } \\
\text { título era falso. }\end{array}$ & 05 & $9,61 \%$ \\
\hline $\begin{array}{l}\text { Consideraram tratar-se da morte do } \\
\text { cantor. }\end{array}$ & 02 & $3,85 \%$ \\
\hline $\begin{array}{l}\text { Consideraram tratar-se de um homôni- } \\
\text { mo do cantor. }\end{array}$ & 45 & $86,54 \%$ \\
\hline Totais: & 52 & $100 \%$ \\
\hline
\end{tabular}




\section{TESTE 3: Da leitura da notícia completa}

Texto 1

PLANTÃO DE POLÍCIA

O novo cardápio da cadeia: Páo com Ovo

Bandido foi preso no Recreio. Ele é apontado como o '02' do tráfico no Fallet e tinha plano pra matar o secretário de Administração Penitenciária na Ponte Rio-Niterói

Um dos homens mais procurados do Rio, Luiz Claudio Gomes, 37 anos, conhecido como Pão com Ovo, foi preso por policiais da 26a DP (Todos os Santos), na noite de sexta-feira. De acordo com a polícia, ele é o segundo homem na hierarquia do tráfico do Morro do Fallet e Fogueteiro, em Santa Teresa, e estava foragido desde que as comunidades foram ocupadas por Unidades de Polícia Pacificadoras (UPPs).

Segundo a polícia, o suspeito vinha sendo monitorado há dois meses. O Disque-Denúncia (2253-1177) chegou a oferecer recompensa de $\mathrm{R} \$ 2$ mil por informaçóes que levassem a polícia ao paradeiro do bandido. Luiz Claudio foi capturado quando passava pela Rua Rabino Henrique Lemsle, altura do número 211, no Recreio dos Bandeirantes. Ao ser abordado pelos agentes, o traficante não resistiu à prisão.

As investigaçóes apontam que o traficante teria fugido para Niterói em agosto do ano passado, quando teria participado da invasão ao Morro dos Marítimos, em Niterói. Na época, a Polícia Militar fez operação para acabar com a guerra entre bandidos de facçóes rivais, e 12 foragidos do Fallet foram capturados.

Contra o acusado havia vários mandados de prisão por tráfico e homicídio. Em julho, o Ministério Público do Rio de Janeiro o denunciou por associação para o tráfico.

O preso também é acusado pela polícia de planejar atentado contra o secretário de Administração Penitenciária, César Rubens. $\mathrm{O}$ ataque seria na Ponte Rio-Niterói. O plano foi descoberto por meio de escutas telefônicas.

$\mathrm{O}$ acusado foi condenado a 25 anos de prisão por homicídio e cumpriu pena de 15 anos por tráfico de drogas. Ainda de acordo com as investigaçóes, o traficante é ligado à facção criminosa Comando Vermelho e estava controlando bocas de fumo em Niterói. 
Texto 2

PLANTÃO DE POLÍCIA

Luan Santana morto a tiros

\section{Xará do cantor levou um balaço na cabeça e outro na perna}

Atingido por um 'meteoro' de tiros, o xará do cantor sertanejo Luan Santana foi assassinado na madrugada de domingo, na periferia de Apucarana, no Paraná. Luan Santana Antunes, 19 anos, foi executado com quatro tiros - um na cabeça, dois nas costas e outro na perna esquerda - no bairro Jardim Ponta Grossa.

O crime ocorreu por volta das $4 \mathrm{~h}$, na esquina das ruas Castro Alves e Pato Branco. O corpo do jovem estava caído ao lado de um televisor de 42 polegadas.

Dependência química

Segundo a polícia, o aparelho de TV encontrado ao lado da vítima pode ser dos próprios familiares. De acordo com parentes de Luan Santana, ele era dependente químico e tinha dívidas com traficantes de crack da região. Ainda segundo alguns familiares do rapaz, no final do ano passado, o homônimo do cantor foi preso sob a acusação de furto.

O autor do assassinato fugiu logo após o crime, sem ser identificado por testemunhas. Apesar da informação de que o rapaz teria dívida com traficantes da região, a polícia local ainda não tem pistas do criminoso.

Uma equipe do Serviço de Atendimento Móvel de Urgência (Samu) foi até o local, onde constatou óbito por disparos de arma de fogo. O crime aconteceu a $65 \mathrm{~km}$ de Maringá, uma das principais cidades do Paraná.

Até o aniversário é próximo

"Não deu tempo. Ele era viciado em drogas, e os traficantes já tinham ido na casa dele para cobrá-lo. Além disso, meu neto havia denunciado uns bandidos à polícia, e eles tinham jurado vingança. Tentei tirá-lo da droga, mas não deu tempo”, lamentou a aposentada Maria Cecília Gervásio Santana, avó de Luan Santana Antunes, enquanto aguardava liberação do corpo no IML. 
Homônimo do cantor sertanejo Luan Santana, a vítima nasceu no mesmo mês do cantor, só que um ano depois, em 3 de março de 1992 . O Luan Santana artista e famoso é de 13 de março de 1991.

(Meia Hora, 01/12/2011)

Após a aplicação e análise, obtivemos os seguintes resultados relativos à macroestrutura semântica inferida pelos informantes:

Tabela 5 - O novo cardápio da cadeia: Pão com Ovo (Etapa 3)

\begin{tabular}{|l|c|c|}
\hline $\begin{array}{c}\text { MACROESTRUTURA ATRIBUÍDA } \\
\text { POR OCASIÃO DA LEITURA } \\
\text { COMPLETA DA NOTÍCIA }\end{array}$ & $\begin{array}{c}\text { QUANTIDADE DE } \\
\text { INFORMANTES }\end{array}$ & PERCENTUAL \\
\hline $\begin{array}{l}\text { Consideraram a prisão de um bandido } \\
\text { apelidado por "Páo com ovo" ser o } \\
\text { tema da notícia. }\end{array}$ & 52 & $100 \%$ \\
\hline Totais: & 52 & $100 \%$ \\
\hline
\end{tabular}

Tabela 6 - Luan Santana morto a tiros (Etapa 3)

\begin{tabular}{|l|c|c|}
\hline $\begin{array}{c}\text { MACROESTRUTURA ATRIBUÍDA } \\
\text { POR OCASIÁO DA LEITURA } \\
\text { COMPLETA DA NOTÍCIA }\end{array}$ & $\begin{array}{c}\text { QUANTIDADE DE } \\
\text { INFORMANTES }\end{array}$ & PERCENTUAL \\
\hline $\begin{array}{c}\text { Consideraram tratar-se da morte de } \\
\text { um (apenas) homônimo do cantor. }\end{array}$ & 52 & $100 \%$ \\
\hline Totais: & 52 & $100 \%$ \\
\hline
\end{tabular}

\section{Discussão dos resultados}

\section{Texto 1}

$\mathrm{Na}$ etapa 1 (E1), 80,77\% dos informantes realizaram antecipaçóes acerca da noção de cardápio alimentar. De acordo com suas respostas, a notícia poderia conter ideias como "reclamaçóes de presos sobre a alimentação", "recompensa em forma de alimento", "privação alimentar intencional como forma de castigo", "mudança no cardápio da cadeia" etc. Dos 52 informantes, 19,23\% 
consideraram tratar-se da prisão de um bandido (Pão com Ovo) ou da prisão de dois bandidos (o primeiro, Páo; o segundo, Ovo).

$\mathrm{Na}$ etapa 2 (E2), esse quadro se altera, adquirindo, a nosso ver, um contorno bastante peculiar, pois, conforme $36,54 \%$ dos informantes, "Pão com Ovo" ainda seria uma referência ao cardápio de determinada cadeia, mas a ser oferecido ao bandido preso no Recreio, bairro carioca. Assim, este grupo reúne ideias segundo as quais as expressóes "Pão com Ovo" e "Bandido" não indicam o mesmo referente. Já 63,46\% estabeleceram uma relação direta entre "Páo com Ovo" (título) e "Bandido" (subtítulo). Sobre essa associação entre o apelido Páo com Ovo e a prisão de um bandido, tivemos um aumento de $44,23 \%$ entre E1 e E2.

Já na etapa 3 (E3), lido o texto completo, 100\% consideraram que a notícia tratou da prisão de um bandido cujo apelido era "Pão com Ovo".

\section{Texto 2}

Em E1, 30,77\% dos informantes não acreditaram haver morte, contudo julgaram que "Luan Santana" seria uma referência ao cantor. Um informante respondeu ser mentira o conteúdo do título porque "nenhum fâ apareceu na TV chorando e nem a Globo disse isso". Outros afirmaram tratar-se de uma notícia falsa. Dos 52 informantes, 57,69\% consideraram a morte do cantor como o fato a ser noticiado e apenas $11,54 \%$ julgaram tratar-se de uma pessoa com o mesmo nome do cantor.

Em E2, obtivemos antecipaçóes mais uniformes, já que $86,54 \%$ dos informantes consideraram tratar-se de um homônimo do cantor; 9,61\% afirmaram falsidade ou, em alguns casos dentro desse grupo, criaram uma hipótese em que a morte era algo figurado; já 3,85\% consideraram a morte como fato a ser noticiado. Nesta etapa, destaque-se o aumento em relaçáo ao percentual de informantes que julgaram "Luan Santana" uma referência a alguém de mesmo nome do cantor (aumento de 75\%) e a diminuição do percentual de informantes que acreditaram na morte (diminuição de 53,84\%). Quer dizer, E2 apresenta significativas diferenças em relação a E1.

Em E3, 100\% consideraram que a notícia possuía como tema a morte de um homônimo do cantor "Luan Santana".

Em relação a nossas hipóteses, nos limites deste experimento, os resultados confirmam a previsão de que a leitura do título propiciaria antecipa- 
ções diversificadas, menos homogêneas. Verificou-se, também, que a leitura do subtítulo provocou alterações na macroestrutura projetada inicialmente pelos informantes. $\mathrm{O}$ experimento ratificou, ainda, nossa hipótese de que as antecipaçóes em E2 seriam as que se aproximariam mais da macroestrutura inferida pelos leitores em E3.

\section{Considerações finais}

O contato com as notícias publicadas no jornal Meia Hora motivou, desde o início, inquietações acerca da produção/ interpretação dos seus títulos. Assim, partindo do pressuposto de que o título náo comporta a macroestrutura semântica da notícia, ou que permite margem para uma interpretação desviante, questionamos a sua tradicional funcionalidade como categoria responsável pelas instruçóes de antecipação.

A nosso ver, esse papel do título envolve um conjunto de estratégias de dramatização, já fixadas como marca/característica desse jornal, do seu estilo de apresentar os fatos. Tais estratégias correspondem a componentes do projeto de captação do jornal não só por serem potentes de realizar um apelo ao emocional do leitor pelo viés da violência, do sexo e da tragédia, mas também porque podem produzir humor e quebrar a expectativa (supostamente) apenas referencial do texto jornalístico. Nesse sentido, a leitura dessas notícias exige competências semânticas, cognitivas e pragmáticas de leitura e interpretação pelo leitor, como mobilizar saberes específicos de um campo semântico empregado pelo jornal; realizar inferências a partir de informaçóes explícitas ou sugeridas; e ser capaz de decifrar o jogo discursivo proposto pelo jornal.

A macroestrutura atribuída às notícias pelos informantes em E3 (terceira etapa do experimento) se distanciou substancialmente daquela inferida na primeira etapa. Isto demonstrou, a nosso ver, que a leitura do texto e a reformulação/destituição de suas hipóteses iniciais de leitura implica a releitura do título.

Outra observação importante decorrente do experimento e que veio corroborar nossas hipóteses de trabalho foi que o subtítulo figurou como a categoria esquemática que indicou ao leitor a necessidade de reformulação de suas hipóteses iniciais de leitura. A partir do subtítulo, os informantes passaram a reformular suas hipóteses iniciais de leitura, que se confirmaram na maioria dos casos na terceira etapa. 
Dessa forma, em relação ao processo ensino/aprendizagem de Língua Portuguesa, chamamos a atenção para a importância do desenvolvimento de atividades de criação de títulos estimulantes e afinados ao seu propósito comunicativo. Por outro lado, consideramos fundamental expor os alunos a textos que exijam, de forma desafiadora, uma leitura atenta.

\section{Referências}

AMARAL, Márcia Franz. Jornalismo popular. São Paulo: Contexto, 2006.

COSTA, Wagner Alexandre dos Santos Costa. Do título ao texto/ Do texto ao título: o processo de estabilização da referência em notícias do jornal popular Meia Hora. Tese de doutorado. Niterói: Universidade Federal Fluminense, 2013, 212 f.

DELL'ISOLA, R. Leituras: inferências e contexto sociocultural. Belo Horizonte: Formato Editorial, 2001.

KLEIMAN, Angela. Texto e leitor: Aspectos cognitivos da leitura. 11 a ed., Campinas: Pontes, 2008.

KOCH. I. Desvendando os segredos do texto. 2a ed. São Paulo: Cortez, 2002. . "A produção de inferências e sua contribuição na construção do sentido". In: As tramas do texto. Rio de Janeiro: Nova Fronteira, 2008a, p. 135-154.

- "Produção e compreensão de textos: a perspectiva da Linguística textual". In: As tramas do texto. Rio de Janeiro: Nova Fronteira, 2008b, p. 201-212.

MARCUSCHI, Luiz Antônio. Leitura como um processo inferencial num universo cultural cognitivo. Leitura: teoria e prática. Revista da Associaçáo de Leitura do Brasil, Campinas, junho de 1985, vol. 5, p. 3 - 19.

ROJO, R. Letramento e capacidades de leitura para a cidadania. São Paulo: SEE: CENP, 2004.

SOLÉ, Isabel. Estratégias de leitura. 6a ed. Porto Alegre: Artmed, 1998.

VAN DIJK, T. A. La noticia como discurso - comprensión, estructura y producción de la información. Barcelona: Paidós Comunicación, 1990.

. El conocimiento y las noticias. Quaderns de Filologia. Estudis de Comunicació. Vol. I, 2002, $249-270$.

- "Modelos na memória - o papel das representaçóes da situação no processamento do discurso" [1988]. In: van Dijk, Teun A. Cognição, discurso e interação (organização e apresentação de Ingedore Koch). 6a ed. São Paulo: Contexto, 2004, p. 158-181. 
VAN DIJK, T. A.; KINTSCH, W. "A caminho de um modelo estratégico do discurso" [1983]. In: van Dijk A. Cognição, discurso e interação (organização e apresentação de Ingedore Koch). 6a ed. São Paulo: Contexto, 2004, p. 9-35.

\title{
CONSTRUCTION OF TITLES DEVIANT IN POPULAR JOURNALISM
}

\begin{abstract}
In this article, we present a study on social cognitive processing of text in popular news. We conducted an experiment on the relationship between the anticipations motivated by reading the title and then the global understanding of the text after a thorough reading. Fifty-two informants performed activities based on two stories drawn from the popular Meia Hora newspaper.
\end{abstract}

KEYWORDS: Sociocognitivism; Reading; Popular journalism.

Recebido em: 07/07/2014 Aprovado em: 13/12/2014 